\title{
JUAN DI DOMÉNICO DI RUGGIERO Adiós al maestro y director
}

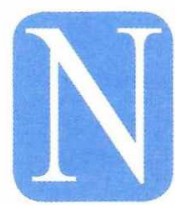

o es fácil aceptar la ausencia de quien ha estado cerca de nuestro trabajo diario durante tantos años. Aunque es natural el desenlace final de las personas que han gozado la longevidad, se siente su ausencia en los momentos de reflexión cuando su consejo acertado fue guía y brújula en la exigente labor editorial.

Conocí al Profesor Juan Di Doménico cuando era estudiante de la Facultad Nacional de Medicina por allá en la década de los sesenta. El me llevó a la naciente revista Tribuna Médica para iniciarme como revisor de los trabajos científicos que los profesores universitarios enviaban para su publicación. Con mi padre y los doctores Guillermo Fergusson y Eugenio Ordóñez me aconsejaron que realizara el año de internado rotatorio en el Hospital de San José. Allí conocería sus dotes de cirujano, tanto en la docencia como en la atención de los pacientes que acudían al hospital. Fue proverbial su revista con llamada a lista a las 7 a.m. de los internos y residentes de la especialidad, para presentar las evoluciones que deberían haberse hecho de madrugada e ingresar de inmediato al quirófano. Su precisión y exactitud en las normas de la vida fueron su gran cualidad que nos orientaría en el desarrollo de nuestra profesión.

Nació en Panamá el 21 de agosto de 1913. Fue el tercero de siete hermanos, los dos mayores Marietta y Donato y los cuatro menores Elisa, Olga, Yolanda e Italia. Su padre Francesco y su madre María Felicia Di Ruggiero provenían de Castelnuovo, pequeña villa cercana a Caserta, a Nápoles y al mar Tirreno.
Huérfano a los seis años tuvo que laborar en los viñedos de la región y cuando pudo salió de Italia, primero hacia África y luego a las Antillas, Panamá y Colombia. Numerosos miembros de las familias Di Doménico y Di Ruggiero se unieron en el exilio voluntario para probar fortuna en diversas actividades. Pero fue su tesón y dedicación por el naciente arte cinematográfico que los llevó a Bogotá, para fundar el famoso Salón Olimpia en la zona de San Diego. Allí se exhibieron películas extranjeras y las producidas por los hermanos Di Doménico hasta 1945 cuando fue derruido para dar paso a la actual carrera novena, como bien lo narran Jorge Nieto y Diego Rojas en el libro Tiempos del Olimpia. En su retiro murió en Villeta donde estaría el prestigioso hotel que administraron sus hijas.

Juan Di Doménico creció en este entorno. Inició su bachillerato en el Gimnasio Moderno de Bogotá y luego regresó para completarlo a su tierra natal. Estudió medicina en la Universidad de Nápoles y después de practicar un tiempo se desplazó a los Estados Unidos donde se convirtió en el experto cirujano general que a su regreso al país se vincularía a la Universidad Nacional y al Hospital de San Juan de Dios. Pronto decidió radicarse en el Hospital de San José donde sería jefe del departamento de cirugía en varias ocasiones, director del Hospital de San José de 1959 a 1960 y además regentó la cátedra en la Universidad Javeriana.

Cuando esta universidad trasladó toda su actividad académica al recién inaugurado Hospital de San 
Ignacio, el Profesor Di Doménico renunció y centró toda su actividad, en asocio con Guillermo Fergusson, Eugenio Ordóñez, Arturo Aparicio Jaramillo y los demás miembros de la Sociedad de Cirugía de Bogotá que decidieron quedarse en San José, para diseñar y programar una nueva facultad de medicina cuyo currículo innovador llenara las expectativas del médico general que el país necesitaba en ese momento. Para entonces era necesario asociarse con una universidad y ante las diferentes perspectivas se optó por un convenio con la Universidad del Rosario, gracias a la comprensiva actitud del rector monseñor José Vicente Castro Silva, asociación que duraría tres décadas.

Fue el, en conjunto con los doctores Mario Negret, Hernando Galvis, Antonio Becerra, Arturo Aparicio, Roberto Jaramillo, y sus colaboradores, quienes idearon y pusieron en funcionamiento los nuevos departamentos quirúrgicos que tanta gloria le han dado a nuestra institución.

Pero fueron talvez las revistas científicas las que cautivaron a nuestro profesor. En los años sesenta fundó el semanario Tribuna Médica con la firme colaboración de la empresa editorial de Salomón Lerner. Cuando se consolidó en Colombia logró extenderla por México, Centroamérica, el área andina y el cono sur. No contento con la colosal difusión americana llegó hasta Europa como Tiempos Médicos en España y Francia, en donde el nombre original ya estaba registrado y contaba con baja circulación. Durante muchos años trabajé con el como Secretario de Re- dacción o bien como director de otras publicaciones médicas que se imprimían en los talleres Lerner, como Consulta y Hospital. Fueron sus enseñanzas las que me formaron en este arte y ciencia del editor científico y será perenne mi gratitud con el Profesor Di Doménico.

Durante algunos años se radicó en la Florida con su esposa Carmen Buraglia, de abolengo italiano, hasta el deceso de ella en 1992, cuando regresó de nuevo al país. Desde entonces tenía en mente la reaparición de Repertorio de Medicina y Cirugía que había suspendido su publicación a mediados del siglo pasado cuando se inició el convenio con la Universidad Javeriana.

Su ideal se cumplió en el año 2000 cuando estas páginas reabrieron para servicio y difusión de los trabajos científicos de nuestros médicos del Hospital de San José y de la Fundación Universitaria de Ciencias de la Salud, FUCS. Desde entonces fui su editor y compartí los logros y las dificultades que a diario enfrentamos quienes nos dedicamos a esta labor.

El recuerdo serio, grato y amable del Profesor, compañero de trabajo y amigo permanecerá en nuestras mentes y será norma espiritual para todos.

Reciban sus hijos Juan Francisco, nuestro discípulo que escogió el litoral caribe para vivir y trabajar, y Claudio, así como a su hermana, nietos y demás familiares, un saludo de condolencia por el reciente fallecimiento.
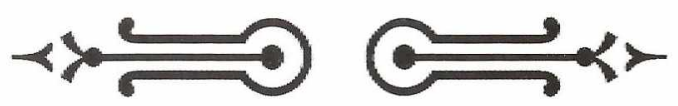